\title{
Principal Component Analysis of Chickpea (Cicer arietinum L.) Germplasm
}

\section{Renuka Shivwanshi* and Anita Babbar}

\author{
Department of Plant Breeding and Genetics, College of Agriculture, \\ J.N.K.V.V. Jabalpur, (M.P.) 482004, India \\ *Corresponding author
}

\begin{abstract}
A B S T R A C T
In order to define selection criteria 434 chickpea genotypes were evaluated under rain-fed conditions during 2015-16 rabi season. Selection of genotypes and traits based on Principal

Keywords

Chickpea, Eigen value, Principal component Analysis.

\section{Article Info}

Accepted: 04 September 2017 Available Online: 10 October 2017 Component analysis. Out of thirteen PCS's identified first 8 PC accounted for $77.68 \%$ of the total variation. The PC1 explained $26.57 \%$ of total variation. While PC2, PC3, PC4, PC5, PC6, PC7 and PC8 exhibited 13.58\%, 8.45\%, 6.54\%, 5.48\%, 6.03, 4.37 and 3.66\% variability, respectively. Genotype IC 84037 was commonly found in PC 1, PC3, PC 6 and PC7 followed by IC 84037 in PC 1, PC 3, PC 6 and PC 7, IC 83812 in PC 1, PC 2, PC 3, and PC 7, IC 83372 in PC 1, PC 3, PC 5, and PC 7, IC83592 in PC 1, PC 4, PC 5 and PC 7 , similar type of genotypes on a common principal component permitting to designate them as seed yield factors. These genotypes may further be utilized in breeding programmes for improving seed yield these genotypes can be considered an ideotype breeding material for selection of traits viz more total number of seed per plant, more effective pods per plant and high biological yield per plant and further utilization in precise breeding programme. The maximum PC value was found in genotype IC 84037 (9.79) followed by, IC 83812(8.46), EC 489919(7.70), IC 83387 (6.42), IC 83813 (6.24). This result has been suggested that these genotypes would be of practical value to chickpea breeders in identifying the genotype with desired trait for utilization in breeding program for genetic improvement.
\end{abstract}

\section{Introduction}

Chickpea is a cool season legume crop and is grown in several countries worldwide as a food source. Chickpea is the third most important food legume crop and India is the largest producer contributing to $65 \%$ of world's chickpea production: it imports chickpea from other countries. However the ever-increasing demand for this legume crop; it is essential to improve the production and area under cultivation. The area under chickpea cultivation decreased due to lack of high yielding varieties and susceptibility to insects and diseases (Hameed et al., 2009).
The yield of chickpea can be improved by selection of superior genotypes which is directly related with the seed yield and utilize these genotypes exclusively in breeding programs to enhance grain yield. Yield is a complex trait which is affected by several factors and environment hence a well-known technique was introduce known as principal component analysis which identified and prioritizes the important traits to minimise the number of traits for effective selection. PCA is a standard tool in modern data analysis because it is a simple, non-parametric method 
for extracting relevant information from confusing data sets. With minimum efforts PCA provides a roadmap for how to reduce a complex data set to a lower dimension to reveal the sometimes hidden simplified structure that often underline it. It reduces the dimensionality of the data, while retaining most of the variation in the data set. PCA accomplishes this reduction by identifying directions, called principal components, along which the variation in the data is maximal by using a few components; each sample can be represented by relatively few numbers instead of by values for thousands of variable. Thus the primary benefit of PCA arises from quantifying the importance of each dimension for describing the variability of a data set. It involves a mathematical procedure that transforms a number of (possibly) correlated variables into a (smaller) number of uncorrelated variables called principal components Muniraja et al., (2011)

\section{Materials and Methods}

The study pertaining to the evaluation of superior chickpea genotype using principal component analysis was conducted in the Seed Breeding Farm, College of Agricultural, JNKVV, Jabalpur (M.P.) during rabi 201516.

The experimental material comprised of 434 different chickpea genotypes evaluated for thirteen quantitative traits, received from NBPGR New Delhi sown in augmented block design. Each plot comprised of 30 rows of 4.0 $\mathrm{m}$ length, row to row distance of $30 \mathrm{~cm}$ and plant to plant distance is $8-10 \mathrm{~cm}$.

According to the Massay (1965) and Jolliffie (1986) PCA is a well-known method of dimension reduction that can be used to reduce a large set of variables to a small set that still contains most of the information in the large set. Therefore, the present investigation was aimed to evaluate the germplasm of chickpea for identify and rank important traits and genotype on the basis of principal component analysis before taking up hybridization programme for evolving better hybrid in chickpea.

\section{Results and Discussion}

Principal component analysis is a simple non parametric method for extracting relevant information from confusing data sets. With minimum efforts, this provide a roadmap for how to reduce a complex data set to a lower dimension to sometimes hidden, simplified structures that often underlines it. PC is a statistical procedure that uses an orthogonal transformation to convert a set of observations of possibly correlated variables into a set of values of linearly uncorrelated variables called principal components the number of principal components is less than or equal to the number of original variables. This transformation is defined in such a way that the first principal component has the largest possible variance (that is accounts for as much of the variability in the data as possible) and each succeeding component in turn has the highest variance possible under the constraint that it is orthogonal to the proceeding components. The resulting vectors are an uncorrelated orthogonal basis set. The principal components are orthogonal because they are the Eigen vectors of the covariance matrix, which is symmetric. In present investigation principal component analysis was performed for yield and yield contributing traits of chickpea

In the present investigation PCA was performed for quantitative traits of chickpea. Out of thirteen, only 8PCs exhibited more than 1.0 Eigen value and showed about 77.6 $8 \%$ variability. Therefore, these 8 PCs were given due important for the further explanation. 
Out of thirteen, the first eight principal components having Eigen values greater than 0.5 altogether explain $77.68 \%$ of the total variation among the 434 genotype. The PC1 explained total variation $26.57 \%$ followed by respectively among the genotypes for the traits under study. PC1 and PC2 showed maximum contributed to the total variation are presented in table 2 . The PC 1 accounted for maximum proportion of total variability in the set of all variables and remaining components accounted for progressively lesser and lesser amount of variation. The PC 1 accounted for maximum variability i.e. $26.57 \%$ which reduced gradually to PC 2 (13.58\%), PC 3 (8.45\%), PC 4 (6.54\%), PC 5 (5.48\%), PC $6(6.03 \%)$, PC $7(4.37 \%)$ and PC $8(3.66 \%) \%$ in the eight PCs. It can be concluded from the above results that yield contributing traits were having the highest variation in PC 1 followed by PC 2 and PC 3.

The objective of principal component analysis is to identify the minimum number of components, which can explain maximum variability out of the total variability and also to rank germplasm on the basis of PC scores. These finding similar to the Mahendra et al., (2015) that the cumulative variance of $77.38 \%$ of total variation. Component 1 had $23.35 \%$ variability and the remaining of
$17.13 \%, 9.93 \%$ and $9.22 \%$ was consolidated in component 3 , component 4 and component 5. Rotated component matrix (Fig. 2) revealed that each PC separately loaded with various phenological and yield attributing traits.

PC 1 which accounted for the highest variability were mostly related yield contributing traits like total number of seed per plant followed by effective pods per plant, biological yield per plant, number of primary branches per plant, number of secondary branches per plant, 100-seed weight, and plant height were important contributions for variability thus. As PC 1 was constituted by most of the yield attributing traits, a intensive selection procedure can be designed to bring out rapid improvement of dependent traits i.e. yield by selecting the lines of PC 1 .

PC2 was dominated by phenological traits viz., days to $50 \%$ flowering, days to flower initiation, days to pod initiation and days to maturity. The main variables of PC3 were harvest index and seed yield per plant are presented in table 1. Thus, PC1 and PC3 allowed for simultaneous selection of yield related traits and it can be regarded as yield factor from this study it was clear that PC 1 and PC3were mostly related to seed yield traits.

Fig.1 Screen plot constructed based on thirteen principal component and their Eigen values

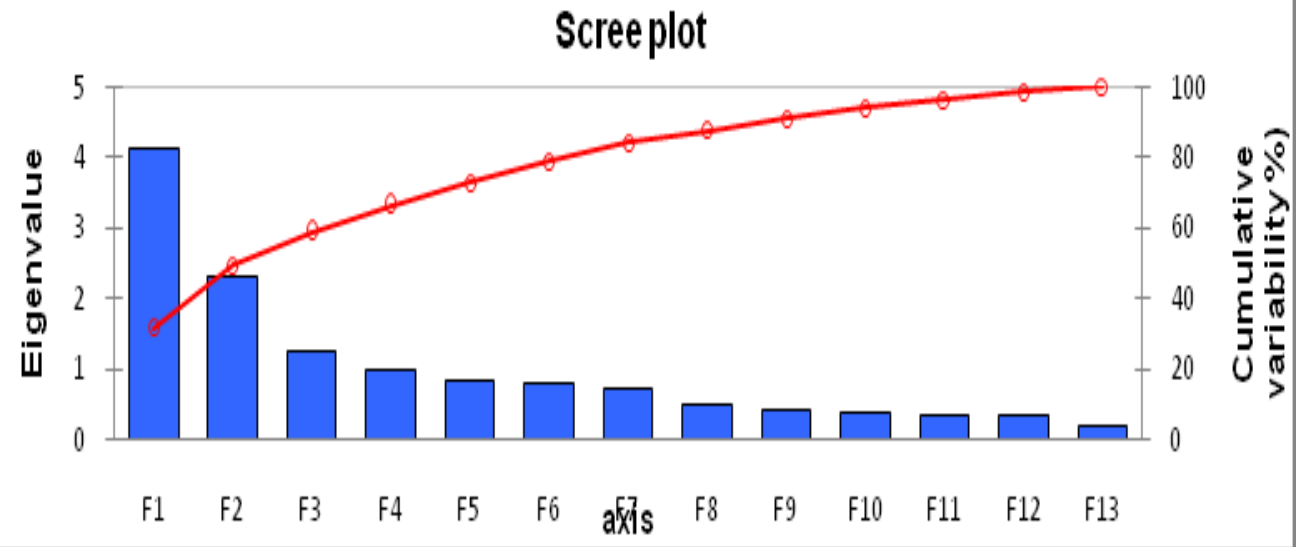


Fig.2 Rotated component matrix

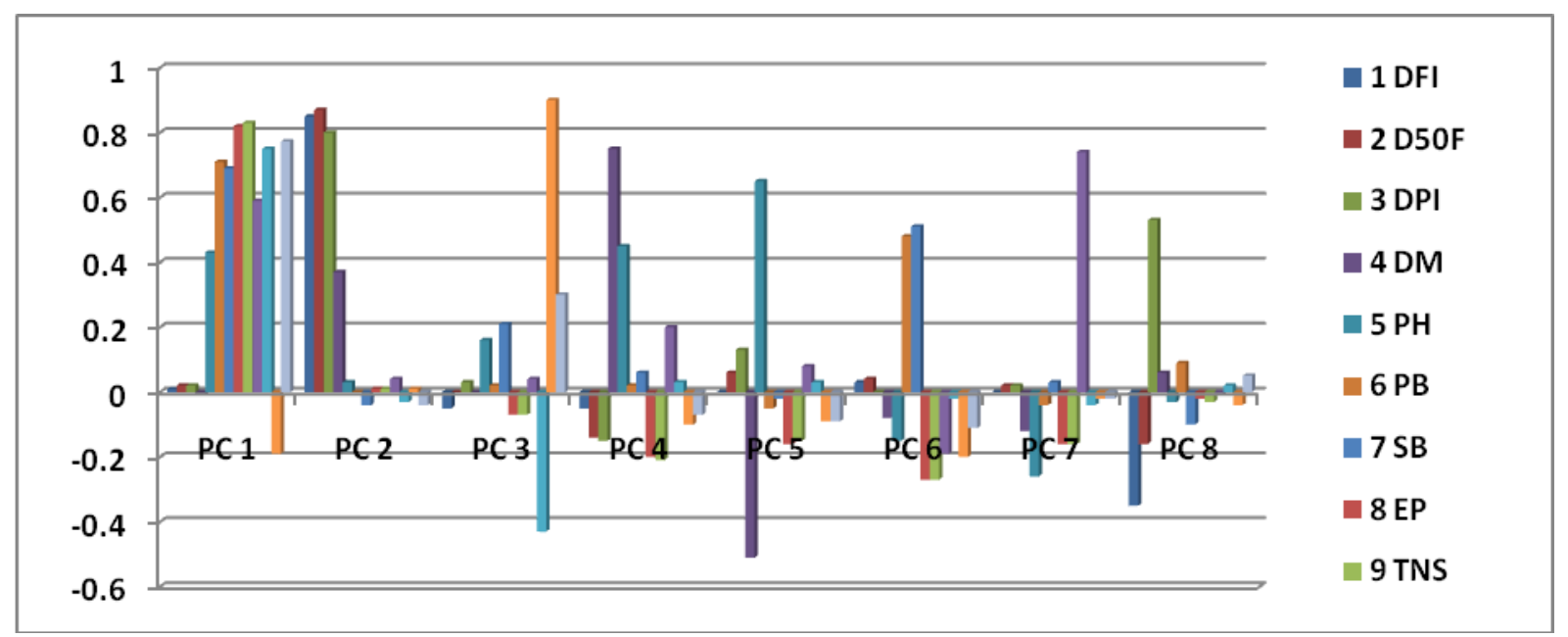

Table.1 Traits having highest values in each PC

\begin{tabular}{|l|l|l|l|l|l|l|l|l|}
\hline & PC1 & PC 2 & PC 3 & PC 4 & PC 5 & PC 6 & PC 7 & PC 8 \\
\hline Traits & $\begin{array}{l}\text { Plant } \\
\text { height }\end{array}$ & $\begin{array}{l}\text { Days to } \\
\text { flower } \\
\text { initiation }\end{array}$ & $\begin{array}{l}\text { Harvest } \\
\text { index } \\
(\%)\end{array}$ & $\begin{array}{l}\text { Days to } \\
\text { maturity }\end{array}$ & $\begin{array}{l}\text { Plant } \\
\text { height } \\
\text { (cm) }\end{array}$ & $\begin{array}{l}\text { Number } \\
\text { of } \\
\text { secondary } \\
\text { branches } \\
\text { per plant }\end{array}$ & $\begin{array}{l}100- \\
\text { seed } \\
\text { weight }\end{array}$ & $\begin{array}{l}\text { Days to } \\
\text { pod } \\
\text { initiation }\end{array}$ \\
\cline { 2 - 8 } & $\begin{array}{l}\text { Number } \\
\text { of } \\
\text { primary } \\
\text { branches } \\
\text { per plant }\end{array}$ \\
\hline $\begin{array}{l}\text { Number } \\
\text { of } \\
\text { secondary } \\
\text { branches } \\
\text { per plant }\end{array}$ & $\begin{array}{l}\text { Days to } \\
\text { flowering } \\
\text { pod } \\
\text { initiation }\end{array}$ & $\begin{array}{l}\text { Seed } \\
\text { yield } \\
\text { per } \\
\text { plant } \\
\text { Days to } \\
\text { pods per } \\
\text { plant }\end{array}$ & $\begin{array}{l}\text { Plant } \\
\text { height } \\
\text { of } \\
\text { primary } \\
\text { branches } \\
\text { per plant }\end{array}$ & & & & & \\
\hline $\begin{array}{l}\text { Total } \\
\text { number of } \\
\text { seed per } \\
\text { plant }\end{array}$ & & & & & & & & \\
\hline $\begin{array}{l}\text { 100-seed } \\
\text { weight }\end{array}$ & & & & & & & & \\
\hline $\begin{array}{l}\text { Seed } \\
\text { yield per } \\
\text { plant }\end{array}$ & & & & & & & & \\
\hline
\end{tabular}


Table.2 PC values of rotation component matrix for thirteen variables of chickpea

\begin{tabular}{|c|c|c|c|c|c|c|c|c|}
\hline Traits & PC1 & PC2 & PC3 & PC4 & PC5 & PC6 & PC7 & PC8 \\
\hline Eigen Value & 4.10 & 2.28 & 1.22 & 0.98 & 0.84 & 0.78 & 0.69 & 4.47 \\
\hline Variability \% & 26.57 & 13.58 & 8.45 & 6.54 & 5.48 & 6.03 & 4.37 & 3.66 \\
\hline Cumulative \% & 31.57 & 49.16 & 58.61 & 66.16 & 72.64 & 78.67 & 84.05 & 87.72 \\
\hline \multicolumn{9}{|l|}{ Traits } \\
\hline Days to flower initiation & 0.009 & $\mathbf{0 . 8 5}$ & -0.05 & -0.05 & 0.00 & 0.03 & -0.00 & -0.35 \\
\hline Days to $50 \%$ flowering & 0.02 & 0.87 & 0.00 & -0.14 & 0.06 & 0.04 & 0.02 & -0.16 \\
\hline Days to pod initiation & 0.02 & 0.80 & 0.03 & -0.15 & 0.13 & 0.00 & 0.02 & $\mathbf{0 . 5 3}$ \\
\hline Days to maturity & -0.01 & 0.37 & 0.00 & 0.75 & -0.51 & -0.08 & -0.12 & 0.06 \\
\hline Plant height $(\mathbf{c m})$ & 0.43 & 0.03 & 0.16 & 0.45 & $\mathbf{0 . 6 9}$ & -0.15 & -0.26 & -0.03 \\
\hline Number of primary branches per plant & 0.71 & 0.00 & 0.02 & 0.02 & -0.05 & 0.48 & -0.04 & 0.09 \\
\hline Number of secondary branches per plant & 0.69 & -0.04 & 0.21 & 0.06 & -0.02 & 0.51 & 0.03 & -0.10 \\
\hline Effective pods per plant & 0.82 & 0.01 & -0.07 & -0.20 & -0.16 & -0.27 & -0.16 & -0.02 \\
\hline Total number of seed per plant & $\mathbf{0 . 8 3}$ & 0.01 & -0.07 & -0.21 & -0.15 & -0.27 & -0.16 & -0.03 \\
\hline 100-seed weight $(\mathrm{g})$ & 0.59 & 0.04 & 0.04 & 0.20 & 0.08 & -0.19 & 0.74 & -0.01 \\
\hline Biologycal yield per plant (g) & 0.75 & -0.03 & -0.43 & 0.03 & 0.03 & --0.02 & -0.04 & 0.02 \\
\hline Harvest index (\%) & -0.19 & 0.01 & 0.90 & -0.10 & -0.09 & -0.20 & -0.02 & -0.04 \\
\hline Seed yield per plant $(\mathrm{g})$ & 0.77 & -0.04 & 0.30 & -0.07 & -0.09 & -0.11 & -0.02 & 0.05 \\
\hline
\end{tabular}

Table.3 PCA scores of chickpea genotypes having positive $>1$ values in each PCs

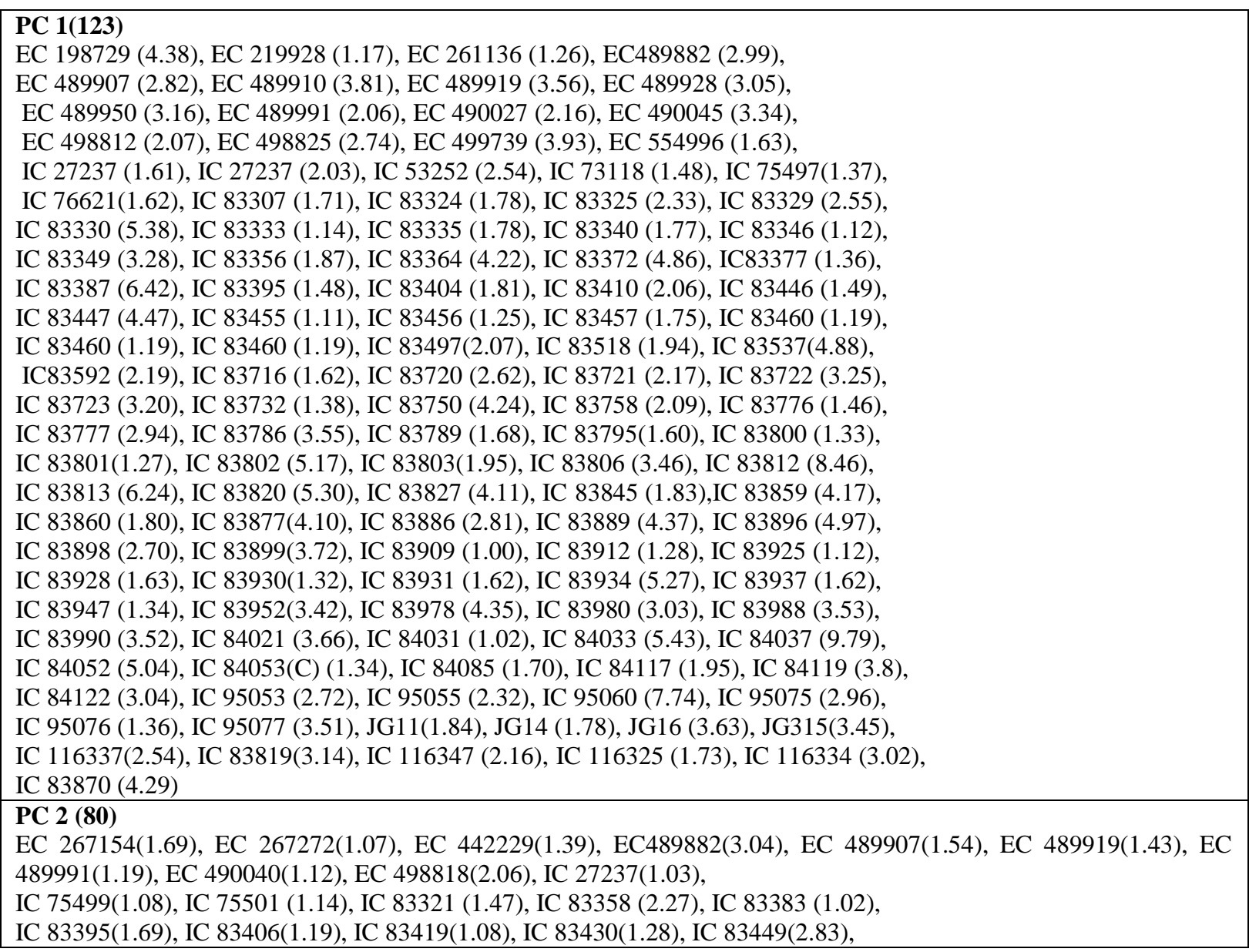


IC 83454 (1.51), IC 83457 (1.25), IC 83462 (1.09), IC 83466 (1.285), IC 83474 (2.72), IC 83480 (1.34), IC 83508 (1.07), IC 83527 (2.55), IC 83541 (1.53), IC 83545 (1.09), IC 83554 (1.04), IC 83644 (1.00), IC 83653 (2.02), IC 83670 (1.10), IC 83679 (2.31), IC 83703 (1.11), IC 83716 (1.31), IC 83729 (2.91), IC 83732 (1.44), IC 83736 (1.85), IC 83744 (1.25), IC 83748 (2.79), IC 83750 (1.03), IC 83756 (1.10), IC 83765 (3.06), IC 83766 (1.15), IC 83779 (1.36), IC 83782 (2.96), IC 83785 (2.13), IC 83787 (2.11), IC 83799 (1.26), IC 83803 (2.11), IC 83811 (1.05), IC 83812 (2.31), IC 83827 (1.64), IC 83843 (1.83), IC 83874 (2.29), IC 83877 (1.05), IC 83880 (1.77), IC 83883 (1.38), IC 83885 (1.21), IC 83904 (1.20), IC 83907 (2.05), IC 83909 (2.19), IC 83912 (1.27), IC 83931 (1.17), IC 83937 (2.29), IC 83985 (1.51), IC 83991 (1.20), IC 84003 (2.40), IC 84011 (1.26), IC 84019 (1.16), IC 84028 (1.60), IC 84033 (1.15), IC 84035 (1.19), IC 84048 (1.11),IC 95052 (1.02), IC 95081 (1.38), IC 83819(2.01) IC 95126 (1.51)

\section{PC 3(64)}

EC 220052(1.23), EC 267272(1.51), EC 267305(1.10), EC489882(4.09), EC 489910 (3.14), EC 489919(7.70), EC 489991 (1.45), EC 498812 (1.11), EC 499739 (2.08), IC 53252 (1.25), IC 83346 (1.15), IC 83347 (1.47), IC 83351 (1.30), IC 83359 (1.02), IC83361 (1.39),

IC 83364 (1.59), IC 83369 (1.52), IC 83372 (1.66), IC 83387 (1.35), IC 83409 (1.41), IC 83411 (4.09), IC 83412 (1.58), IC 83418 (4.71), IC 83419 (2.33), IC 83420 (2.34), IC 83424(2.23), IC 83435(1.91), IC 83436(4.15), NA(3.39), IC 83444 (2.22), IC 83453 (1.29), IC 83459 (1.13), IC 83460 (1.61), IC 83469 (2.31), IC 83471 (3.71), IC 83474 (2.38),

IC 83480 (1.30), IC 83490 (1.31), IC 83500 (1.79), IC 83502 (1.12), IC 83509 (2.31), IC 83510 (2.88), IC 83523 (1.91), IC 83527 (1.17), IC 83528 (1.36), IC 83529 (1.83), IC 83531 (1.00), IC 83538 (1.14), IC 83541 (2.84), IC 83542 (3.11), IC 83543 (2.53), IC 83545 (1.06), IC 83551 (1.13), IC 83554 (1.87), IC 83556 (1.79), IC 83561 (1.36), IC 83704 (1.40), IC 83812 (3.97), IC 83813 (1.49), IC 84001 (1.02), IC 84037 (2.21), IC 95060 (1.16), JG11(2.25), JG315 (1.15)

\section{PC 4 (26)}

EC 267154 (1.11), EC 555106 (1.24), IC 83324 (1.66), IC 83330 (1.34), IC 83344 (1.54), IC 83431 (1.69), IC 83523 (1.34), IC 83528 (1.06), IC 83551 (1.10), IC83592 (1.04), IC 83708 (1.19), IC 83721 (1.160), IC 83722 (1.21), IC 83758 (1.04), IC 83847 (1.12), IC 83913 (1.06), IC 83952 (1.02), IC 83980 (1.08), IC 83996 (1.19), IC 84034 (1.00), IC 84122 (1.09), JG11 (2.25), JG315 (1.15), JG11 (1.22), JG16 (1.36), IC 116334 (1.05)

\section{PC 5(36)}

EC 267154 (2.45), IC 73118 (1.00), IC 83321 (1.19), IC 83324 (1.04), IC 83344 (1.24), IC 83347(1.69), IC 83358(1.11), IC83362(2.03), IC 83372(1.16), IC83377(1.53), IC 83460 (1.15), IC 83493 (1.29), IC 83502 (1.00), IC 83523 (1.36), IC 83545 (1.35), IC 83551 (1.08), IC83592 (1.83), IC 83679 (1.23), IC 83686 (1.20), IC 83709 (1.28), IC 83716 (1.10), IC 83730 (1.12), IC 83827 (1.08), IC 83896 (1.02), IC 83931 (1.29), IC 83934 (1.25), IC 83948 (1.14), IC 83953 (1.09), IC 83978 (1.07), IC 83991 (1.27), IC 84021 (1.41), IC 95053 (1.00), IC 95075 (1.02), JG315(1.40), IC 116337(1.30), IC 83819(1.02)

\section{PC 6(24)}

EC 267265(1.32), EC 267305(2.06), EC 267308 (1.41), EC 442229 (2.03), EC 528350 (1.15), EC 538502 (1.07), EC 555217 (1.18), IC 76621 (1.17), IC 83364 (1.48), IC $83462(1.28)$,

IC 83546 (1.34), IC 83756 (1.27), IC 83784 (1.48), IC 83885 (1.25), IC 83963 (1.22), IC 83974 (1.12), IC 83977 (1.02), IC 84000 (1.07), IC 84037 (7.52), IC 95074 (1.09), IC 116337(1.04), JG14 (1.09), IC 116337 (1.04), IC 116482 (1.59),

\section{PC 7 (32)}

EC 442229(1.28), EC 490027(2.54), IC 83372(2.05), IC 83387(1.04), IC 83432(1.47),

NA(1.06), IC83456 (1.80), IC 83460(1.30), IC 83466(1.24), IC 83539 (2.81), IC 83554 (1.25), IC 83565 (1.03), IC83592 (1.35), IC 83721 (1.30), IC 83741 (1.32), IC 83757 (1.18),

IC 83758 (3.00), IC 83784 (1.12), IC 83812 (2.41), IC 83813 (3.13), IC 83843 (1.62), IC 83859 (1.17), IC 83883 (1.04), IC 83889 (1.61), IC 83988 (1.35), IC 84052 (1.94), IC 84085 (1.16), IC 84117 (1.72), IC 84119 (1.71), IC 95060 (1.08), IC 95075 (1.16), IC $528352(1.44)$

\section{PC 8(4)}

IC 83830 (1.03), IC 84005 (1.03), IC 84037 (2.06), JG 11(1.14) 
Screen plot explain the percentage of variation associated with each principal component obtained by drawing a graph between Eigen value and principal component number (Fig. 1). These results are getting support from the findings of Rekha et al., (2013) that the first principal component (PC1) high significant positive loading of number of secondary branches per plant (0.445) followed by number of pods per plant (0.431) and plant height (0.339). The second principal component (PC2) accounted 18.88 per cent of total variance and it reflected significant positive loading of days to maturity (0.336) followed by days to $50 \%$ flowering (0.287) and protein content (0.259).

Genotype IC 84037 was common in PC 1, PC 3, PC 6 and PC 7, while IC 83812 was common in PC 1, PC 2, PC 3 and PC 7. Genotype IC 83372 was found in PC 1, PC 3, PC 5, and PC 7, whereas IC83592 was familiar in PC 1, PC 4, PC 5 and PC 7. EC 267154 was frequently present in PC 2, PC 4 and PC 5. Genotypes EC489882 and EC 489991 were common in PC 1, PC 2 and PC 3, whereas IC 83324 was common in PC 1, PC 4 and PC 5. IC83377 regularly found in PC 1, PC 5 and PC 7. IC 83387 and IC 83813 were common in PC 1, PC 3 and PC 7. IC 83523 and IC 83551 were common in PC 3, PC 4 and PC 5. IC 95060 was frequently present in PC 1, PC 3 and PC 7. IC 116337 was common in PC 1, PC 5 and PC 6. IC 83819 was frequently present in PC 1; PC 2 and PC 5 are presented in table 3.

On the basis of PC scores which is found to be common in all the principal components (PC 1, PC 2, PC 3, PC4, PC 5, PC 6, PC 7 and $\mathrm{PC} 8)$ the maximum positive Eigen value (>4.0) is found in PC 1(IC 84037 (9.79), IC 83812 (8.46), IC 95060 (7.74), IC 83387 (6.42), IC 83813 (6.24), IC 84033 (5.43), IC 83330 (5.38), IC 83820 (5.30), IC 83934 (5.27), IC 84052 (5.04), IC 83896 (4.97), IC
83537(4.88), IC 83372 (4.86); PC 3 EC 489919(7.70), EC489882(4.09), IC 83418 (4.71), IC 83436(4.15), IC 83411 (4.09) and in PC 6 IC 84037 (7.52) are explain in table 3. This indicated the presence of fair amount of genetic diversity and is useful for future breeding program.

Earlier scientist reported that that a high value of PC scores can be used for selection and for further utilization in future breeding programme. These genotypes which are common in more than $1 \mathrm{PCs}$ are indicated that selection of genotype from these PCs is useful in further crop improvement programme. These findings are also confirmation with Akande (2007), Ojo et al., (2012), Miladinovic et al., (2006), Iqbal et al., (2008) Ghafoor et al., (2000), Toker and Cagirgan (2004) and Amrita et al., (2014).

\section{References}

Akande, S.R., 2007. Multivariate analysis of the genetic diversity of pigeon pea germplasm from south-west Nigeria. Journal of Food Agriculture and Environment, 5(1): 224.

Amrita, B., Shrivastava, A., Bisen, R. And Mishra, S., Study of Principal Component Analyses for Yield Contributing Traits in Fixed Advanced Generations of Soybean (Glycine max (L.) Merrill). Soybean Research, Pp. 44.

Ghafoor, A., Sharif, A., Ahmad, Z., Zahid, M.A. and Rabbani, M.A., 2001. Genetic diversity in blackgram (Vigna mungo L. Hepper). Field Crops Research, 69(2): 183-190.

Hammed, M.Y., Albadrany MM 2009. Stability of chickpea (Cicer arietinum L.) varieties under rainfed conditions in northern Iraq. Afric. Crop. Sci. 8: 219224.

Iqbal Zafar, Muhammad Arshad, Muhammad Ashraf, Mahmood Tariq and Waheed 
Abdul. 2008. Valuation of soybean [Glycine max (1.) Merrill] germplasm for some important morphological traits using multivariate analysis. Pakistan Journal of Botany 40(6): 2323-8.

Jolliffe, I., 2002. Principal component analysis. John Wiley \& Sons, Ltd.

Mahendran, R., Veerabadhiran, P., Robin, S. and Raveendran, M., 2015. Principal component analysis of rice germplasm accessions under high temperature stress. International Journal of Agricultural Science and Research, 5(3), 355-359.

Massey, W. F., 1965. Principal components regression in exploratory statistical research. J. Amer. Statist. Assoc. 60, 234-246

Miladinovic Jegor, Hideki Kurosaki, Joe W Burton, Milica Hrustic and Dragana Miladinovic. 2006. The adaptability of short season soybean genotypes to varying longitudinal regions. European Journal of Agronomy 25: 243-9
Muniraja, C., Satish, R.G., Raju, C. and Hart, M., 2011. Principal component analysis among genotypes of chickpea (Cicer arietinum L.). International Journal of Agricultural Sciences, 7(2), 382-386.

Ojo, D.K., Ajayi A O and Oduwaye O A. 2012. Genetic relationships among soybean accessions based on morphological and RAPDs techniques. Pertanika Journal of Tropical Agricultural Science 35(2): 237-48.

Rekha, R., Prasanthi, L., Sekhar, M.R. and Priya, M.S., 2013. Principal Component and Cluster Analyses in Pigeonpea [Cajanus cajan (L.) Mill Sp]. International Journal of Applied Biology and Pharmaceutical Technology. 4(4): 424-430.

Toker, C., and Ilhan Cagirgan, M., 2004. The use of phenotypic correlations and factor analysis in determining characters for grain yield selection in chickpea (Cicer arietinum L.). Hereditas, 140(3): 226-228.

\section{How to cite this article:}

Renuka Shivwanshi and Anita Babbar. 2017. Principal Component Analysis of Chickpea (Cicer arietinum L.) Germpasm. Int.J.Curr.Microbiol.App.Sci. 6(10): 166-173. doi: https://doi.org/10.20546/ijcmas.2017.610.021 